\title{
Partitioning of $\mathrm{CH}_{4}$ and $\mathrm{CO}_{2}$ Production Originating from Rice Straw, Soil and Root Organic Carbon in Rice Microcosms
}

\author{
Quan Yuan, Judith Pump, Ralf Conrad*
}

Max-Planck-Institute for Terrestrial Microbiology, Marburg, Germany

\begin{abstract}
Flooded rice fields are an important source of the greenhouse gas $\mathrm{CH}_{4}$. Possible carbon sources for $\mathrm{CH}_{4}$ and $\mathrm{CO}_{2}$ production in rice fields are soil organic matter (SOM), root organic carbon (ROC) and rice straw (RS), but partitioning of the flux between the different carbon sources is difficult. We conducted greenhouse experiments using soil microcosms planted with rice. The soil was amended with and without ${ }^{13} \mathrm{C}$-labeled RS, using two ${ }^{13} \mathrm{C}$-labeled RS treatments with equal RS $(5 \mathrm{~g}$ $\mathrm{kg}^{-1}$ soil) but different $\delta^{13} \mathrm{C}$ of RS. This procedure allowed to determine the carbon flux from each of the three sources (SOM, ROC, RS) by determining the $\delta^{13} \mathrm{C}_{\text {of }} \mathrm{CH}_{4}$ and $\mathrm{CO}_{2}$ in the different incubations and from the $\delta^{13} \mathrm{C}$ of RS. Partitioning of carbon flux indicated that the contribution of $\mathrm{ROC}$ to $\mathrm{CH}_{4}$ production was $41 \%$ at tillering stage, increased with rice growth and was about $60 \%$ from the booting stage onwards. The contribution of $\mathrm{ROC}$ to $\mathrm{CO}_{2}$ was $43 \%$ at tillering stage, increased to around $70 \%$ at booting stage and stayed relatively constant afterwards. The contribution of RS was determined to be in a range of $12-24 \%$ for $\mathrm{CH}_{4}$ production and $11-31 \%$ for $\mathrm{CO}_{2}$ production; while the contribution of SOM was calculated to be $23-35 \%$ for $\mathrm{CH}_{4}$ production and 13-26\% for $\mathrm{CO}_{2}$ production. The results indicate that ROC was the major source of $\mathrm{CH}_{4}$ though RS application greatly enhanced production and emission of $\mathrm{CH}_{4}$ in rice field soil. Our results also suggest that data of $\mathrm{CH}_{4}$ dissolved in rice field could be used as a proxy for the produced $\mathrm{CH}_{4}$ after tillering stage.
\end{abstract}

Citation: Yuan Q, Pump J, Conrad R (2012) Partitioning of $\mathrm{CH}_{4}$ and $\mathrm{CO}_{2}$ Production Originating from Rice Straw, Soil and Root Organic Carbon in Rice Microcosms. PLoS ONE 7(11): e49073. doi:10.1371/journal.pone.0049073

Editor: Kathleen Treseder, University of California Irvine, United States of America

Received July 20, 2012; Accepted October 3, 2012; Published November 5, 2012

Copyright: (c) 2012 Yuan et al. This is an open-access article distributed under the terms of the Creative Commons Attribution License, which permits unrestricted use, distribution, and reproduction in any medium, provided the original author and source are credited.

Funding: The study is part of the ICON Project funded by the German Research Foundation and the SYNMICRO Program funded by the Ministry of Hessen. The funders had no role in study design, data collection and analysis, decision to publish, or preparation of the manuscript.

Competing Interests: The authors have declared that no competing interests exist.

*E-mail: conrad@mpi-marburg.mpg.de

\section{Introduction}

Flooded rice fields are an important source of the greenhouse gas $\mathrm{CH}_{4}$ [1,2]. Methane and $\mathrm{CO}_{2}$ are end products of anoxic degradation of organic matter in rice field soil [3]. The organic matter is mainly derived from three sources [4]: (1) soil organic matter (SOM), (2) root organic carbon (ROC) including root exudates and sloughed-off dead root, and (3) dead plant organic matter, such as rice straw (RS), which is often applied in large amounts (up to $12 \mathrm{tha}^{-1}$ annually) to maintain soil fertility [5-7]. Methane production is partitioned mainly between these three types of organic matter. Knowledge of partitioning is important for improving process-based modeling of $\mathrm{CH}_{4}$ emission from rice fields $[8,9]$, which is the basis for predicting methane flux and assessing the impact of agricultural management and global change.

Quantification of carbon partitioning can in principle be achieved by pulse-labeling of rice plant with ${ }^{13} \mathrm{CO}_{2}$ or ${ }^{14} \mathrm{CO}_{4}$ [10-12]. Recently, free-air $\mathrm{CO}_{2}$ enrichment (FACE) using ${ }^{13} \mathrm{C}$ depleted $\mathrm{CO}_{2}$ was used for determining the contribution of ROC to production of $\mathrm{CO}_{2}$ and $\mathrm{CH}_{4}$ in rice field soil [13]. However, pulse-labeling only assesses the immediate contribution of root exudates, while the contribution of sloughed-off dead root cells cannot be fully accounted for [13-16]. Since FACE experiments apply elevated $\mathrm{CO}_{2}$ concentrations, photoassimilation of $\mathrm{CO}_{2}$ may be enhanced and thus increase the contribution of plants and soil organic matter to carbon flux [17-19]. Furthermore, most studies of carbon flux partitioning in rice fields have been done without application of straw, so that full partitioning of the origin of carbon flux into SOM, ROC and RS was not possible [4]. However, application of RS should be taken into account, since RS may not only be used as substrate for $\mathrm{CH}_{4}$ production, but might also enhance $\mathrm{CH}_{4}$ production from other carbon sources [20,21].

The partitioning of the $\mathrm{CH}_{4}$ production from different sources of organic carbon (SOM, ROC, RS) can be achieved, if these have different isotopic signatures. However, a major difficulty during partitioning the sources of $\mathrm{CH}_{4}$ is caused by the carbon isotopic fractionation during the conversion of organic matter to $\mathrm{CH}_{4}$, which is typically 10-70\% [22]. Nevertheless, the relative contribution of acetoclastic versus hydrogenotrophic methanogenesis to $\mathrm{CH}_{4}$ production has been determined successfully in environments such as rice field soil [23] and lake sediments [24], after the isotopic fractionation factors in both methanogenic pathways were determined. The $\delta^{13} \mathrm{C}$ values of $\mathrm{CH}_{4}$ from the two pathways are substantially different, since the isotopic fractionation factors of the two pathways are largely different $[22,24,25]$. Analogously, it is possible to partition the sources of $\mathrm{CH}_{4}$ if the $\delta^{13} \mathrm{C}$ of $\mathrm{CH}_{4}$ derived from each carbon source in the rice field soil is known. Normally, the $\mathrm{CH}_{4}$ derived from SOM, ROG and RS has similar $\delta^{13} \mathrm{C}$ values, since all the organic matter has eventually been derived from rice plant material $[23,26]$. However, this 
problem may be solved by cultivation of rice in soil amended with ${ }^{13}$ C-labeled RS.

The aim of this study was to determine the partitioning of the carbon flux involved in methanogenic degradation of carbon sources by determining the $\delta^{13} \mathrm{C}$ of $\mathrm{CH}_{4}$ derived from ROC. We therefore prepared rice microcosms with two treatments of ${ }^{13} \mathrm{C}$ labeled RS, both having the same amount of RS $\left(5 \mathrm{~g} \mathrm{~kg}^{-1}\right.$ soil, equals about $5 \mathrm{t} \mathrm{ha}^{-1}$ ) but different content of ${ }^{13} \mathrm{C}$. We determined the produced $\mathrm{CH}_{4}$ and $\mathrm{CO}_{2}$ by collecting soil cores and incubating samples anoxically [27].

\section{Materials and Methods}

\section{Planted and unplanted rice microcosms}

Soil samples were provided by the Italian Rice Research Institute in Vercelli. Soil was taken from a drained paddy field in spring 2009 and was air dried and stored at room temperature. The soil was sieved $(<2 \mathrm{~mm})$ prior to use. The characteristics of the soil have been described previously [28]. Planting pots (upper diameter $=19 \mathrm{~cm}$; lower diameter $=14 \mathrm{~cm}$; height $=16 \mathrm{~cm}$ ) were filled with $2 \mathrm{~kg}$ dry soil and turned into a slurry with demineralized water.

For planted rice microcosms, in total 48 pots were prepared, 16 pots for the unamended control, and 16 pots each for RS treatment I and RS treatment II. Fertilizer solution $(50 \mathrm{ml}$ of a solution containing per liter: $10 \mathrm{~g}$ urea, $7.6 \mathrm{~g} \mathrm{K \textrm {K } _ { 2 }} \mathrm{PO}_{4}$ ) was added to each pot as basal fertilizer. For both RS treatments, $10 \mathrm{~g}$ powder of RS was added to each pot and mixed thoroughly into the soil slurry. The $\delta^{13} \mathrm{C}$ values of RS added in treatment I and II were $213.0 \%$ and $474.7 \%$, respectively. These $\delta^{13} \mathrm{C}$ values were obtained by adding desired amount of ${ }^{13} \mathrm{C}$-labeled $\left(\delta^{13} \mathrm{C}=1859.9 \%\right.$ ) and unlabeled $\left(\delta^{13} \mathrm{C}=-27.6 \%\right)$ RS separately into each pot. The ${ }^{13} \mathrm{C}$-labeled $\mathrm{RS}$ was prepared by growing rice plants in the greenhouse until the late vegetative stage. The plants were covered with a $18-\mathrm{L}$ acrylic chamber, $1 \%{ }^{13} \mathrm{CO}_{2}$ (final concentration; 99 atom\%, Sigma, Germany) was added to the headspace, incubated for 5 days $\left(12 \mathrm{~h}\right.$ light, $\left.25^{\circ} \mathrm{C}\right)$, and then harvested. The unlabeled RS was from rice plant grown in the same manner without feeding on ${ }^{13} \mathrm{CO}_{2}$. These rice plants were dried and ground to powder. After 3 days of incubation in the greenhouse, all the pots were planted with one 12-day old rice seedling (Oryza sativa var. KORAL type japonica), and were flooded with demineralized water to give a water depth of $5 \mathrm{~cm}$ above the soil surface. The water depth was maintained throughout the experimental period. The rice microcosms were incubated in the greenhouse with a relative humidity of $70 \%$, a $12-$ h photoperiod and a $28 / 22^{\circ} \mathrm{C}$ day/night temperature cycle. The day of transplantation was taken as day zero. On day 21 , a second dose of $30 \mathrm{ml}$ fertilizer solution was added to each microcosm. At each sampling time (day 41, 55, 70 and 90), 12 rice microcosms were sacrificed (4 replicates for control and for each treatment). For unplanted microcosms, the preparation was the same as for planted ones, but without rice plant in the pots. In total, 12 pots were prepared with 4 pots each for the unamended control, RS treatment I and RS treatment II.

\section{$\mathrm{CH}_{4}$ flux, soil pore water and plant parameters}

Rates of $\mathrm{CH}_{4}$ emission was measured on day 41, 55, 70 and 90 of incubation in the greenhouse as described previously [27]. For flux measurements, planted rice microcosms were covered by flux chambers, and gas samples were taken every 30 min for $2 \mathrm{~h} . \mathrm{CH}_{4}$ emission rates were determined from the slope of the linearly increasing $\mathrm{CH}_{4}$ mixing ratio and expressed in $\mathrm{mmol} \mathrm{CH}_{4} \mathrm{~m}^{-2}$ $\mathrm{h}^{-1}$.
Samples for the determination of the isotopic signature $\left(\delta^{13} \mathrm{CH}_{4}\right)$ of the emitted $\mathrm{CH}_{4}$ were taken in glass containers $(100 \mathrm{ml})$. The first sample was taken directly after closure of the chambers, the second sample was taken at the end of the 2-h closure period. The isotopic signature of the emitted $\mathrm{CH}_{4}$ was calculated according to [27].

Pore water samples were collected into Venoject bloodcollecting tubes (Terumo Europe N.V., Belgium) from the rhizosphere (3 cm depth) and bulk $(9 \mathrm{~cm}$ depth) soil of rice microcosms using Rhizon pore water samplers (Rhizosphere Research Products, the Netherlands). After heavy shaking by hand, the headspace of the tubes was sampled using a pressure lock syringe and directly analyzed for $\mathrm{CH}_{4}$ and $\mathrm{CO}_{2}$ and $\delta^{13} \mathrm{C}$. The $\mathrm{CH}_{4}$ and $\mathrm{CO}_{2}$ concentration in the soil pore water was calculated as described previously [27].

Plant height, tiller number and aboveground biomass were determined. For dry weight determination, samples were dried for $48 \mathrm{~h}$ at $60^{\circ} \mathrm{C}$.

\section{$\mathrm{CH}_{4}$ and $\mathrm{CO}_{2}$ production}

Production rates of $\mathrm{CH}_{4}$ and $\mathrm{CO}_{2}$ and respective $\delta^{13} \mathrm{C}$ values were determined by collecting soil core samples in rice microcosms on day 41, 55, 70 and 90 of incubation in the greenhouse [27]. After cutting off the rice plant, the surface water layer was removed. Soil cores were taken in each pot with stainless steel corer (Ø $22 \mathrm{~mm}, 210 \mathrm{~mm}$ in length). Two to three soil cores (about $100 \mathrm{~g}$ in total) were collected from each pot and transferred into a $250-\mathrm{ml}$ bottle. The soil samples were turned into slurry using $\mathrm{N}_{2}$-gassed deionized sterile water so that the ratio of dry weight of soil to water was 1:1. After flushing the samples with $\mathrm{N}_{2}$, the bottles were sealed with butyl rubber stoppers and, after shaking, flushed again with $\mathrm{N}_{2}$ to remove residual $\mathrm{O}_{2}$ and $\mathrm{CH}_{4}$. Incubation was performed statically at $25^{\circ} \mathrm{C}$ in the dark for $24 \mathrm{~h}$. Headspace samples were taken every $12 \mathrm{~h}$ after shaking the bottles, and analyzed for concentration of $\mathrm{CH}_{4}$ and $\mathrm{CO}_{2}$ and their $\delta^{13} \mathrm{C}$. The $\mathrm{CH}_{4}$ and $\mathrm{CO}_{2}$ production from planted soil microcosms was due to decomposition of SOM plus ROC (unamneded control) or of SOM, ROC plus RS (RS treatments). $\mathrm{CH}_{4}$ production rates were calculated by linear regression of the $\mathrm{CH}_{4}$ increase with incubation time, and expressed in nmol $\mathrm{CH}_{4} \mathrm{~g}_{\mathrm{dw}}{ }^{-1} \mathrm{~h}^{-1}$ of soil. The $\mathrm{CO}_{2}$ production rates were determined analogously.

For unplanted soil microcosms, the methods for collection and incubation of soil core samples were similar, but these pots were not sacrificed, but at each sampling day (day 41, 55, 70 and 90), a $60-\mathrm{g}$ soil core was taken from the pot. After removal of the soil core the residual soil in the pot was compacted, and water was added to maintain a water level of $5 \mathrm{~cm}$ depth. Using this procedure about $2.1 \%$ of the total amount of soil in the pot was collected during each sampling. The $\mathrm{CH}_{4}$ and $\mathrm{CO}_{2}$ production from unplanted soil microcosms was only due to decomposition of SOM (unamneded control) or of SOM plus RS (RS treatments).

\section{Analytical techniques}

The gas samples were analyzed for $\mathrm{CH}_{4}$ and $\mathrm{CO}_{2}$ using a gas chromatograph (GC) equipped with flame ionization detector (FID) [29]. Stable isotopic analysis of gas samples $\left(\mathrm{CH}_{4}\right.$ and $\left.\mathrm{CO}_{2}\right)$ from pore water and soil core incubation were performed directly using the GCG-IRMS, samples from flux measurements (low in $\mathrm{CH}_{4}$ ) were preconcentrated on a Precon (Finnigan, Bremen, Germany). The principal operation of the GCG-IRMS has been previously described [30,31]. The isotope reference gas was $\mathrm{CO}_{2}$ (99.998\% purity; Messer-Griessheim, Düsseldorf, Germany) calibrated with the working standard methyl stearate (Merck). The latter was intercalibrated at the Max-Planck-Institute for Biogeo- 
chemistry, Jena, Germany (courtesy of Dr. W.A. Brand) against NBS 22 and USGS 24, and reported in the delta notation vs. VPDB: $\delta^{13} \mathrm{C}=10^{3}\left(R_{\mathrm{sa}} / R_{\mathrm{st}}-1\right)$, with $\mathrm{R}={ }^{13} \mathrm{C} /{ }^{12} \mathrm{C}$ of sample (sa) and standard (st), respectively. The precision of repeated analysis was $\pm 0.2 \%$, when $1.3 \mathrm{nmol} \mathrm{CH}_{4}$ were injected [23]. The determination of the stable isotopic signatures of dried plant and soil samples was carried out at the Institute for Soil Science and Forest Nutrition (IBW) at the University of Göttingen, Germany.

\section{Calculations}

1. Fraction of $\mathbf{C H}_{4}$ production from ROC $\left(\boldsymbol{f}_{\boldsymbol{R} O C}\right)$. The fraction of $\mathrm{CH}_{4}$ derived from ROC $\left(f_{\mathrm{ROC}}\right)$ can be determined from the following mass balance equation:

$$
\delta^{13} C_{C_{4}}=f_{R O C} \delta^{13} C_{C H_{4}-R O C}+\left(1-f_{R O C}\right) \delta^{13} C_{C H_{4}-S O R}
$$

where $\delta^{13} \mathrm{C}_{\mathrm{CH} 4}=\delta^{13} \mathrm{C}$ of $\mathrm{CH}_{4}$ produced (or dissolved) in the planted rice microcosms at each sampling time; $\delta^{13} \mathrm{C}_{\mathrm{CH} 4-\mathrm{ROC}}=$ $\delta^{13} \mathrm{C}$ of $\mathrm{CH}_{4}$ formed from ROC (determination see below); $\delta^{13} \mathrm{C}_{\mathrm{CH} 4-\mathrm{SOR}}=\delta^{13} \mathrm{C}$ of $\mathrm{CH}_{4}$ formed from SOM plus RS, i.e. the $\mathrm{CH}_{4}$ produced (or dissolved) in the unplanted soil treated with RS. The equation can be transformed into the following two equations for RS-treatment I and II, respectively:

$$
\begin{gathered}
f_{R O C}=\frac{\delta^{13} C_{C_{4}-I}-\delta^{13} C_{C_{4}-S O R-I}}{\delta^{13} C_{C H_{4}-R O C}-\delta^{13} C_{C_{4}-S O R-I}} \\
f_{R O C}=\frac{\delta^{13} C_{C H_{4}-I I}-\delta^{13} C_{C H_{4}-S O R-I I}}{\delta^{13} C_{C H_{4}-R O C}-\delta^{13} C_{C H_{4}-S O R-I I}}
\end{gathered}
$$

Since $f_{\mathrm{ROC}}$ and $\delta^{13} \mathrm{C}_{\mathrm{CH} 4-\mathrm{ROC}}$ should be the same in treatment I and II, $\delta^{13} \mathrm{C}_{\mathrm{CH} \text {-ROC }}$ can be calculated by solving equations (2) and (3):

$$
\begin{aligned}
& \delta^{13} C_{C_{4}-R O C}= \\
& \frac{\delta^{13} C_{C H_{4}-I} \delta^{13} C_{C_{4}-S O R-I I}-\delta^{13} C_{C H_{4}-I I} \delta^{13} C_{C H_{4}-S O R-I}}{\delta^{13} C_{C H_{4}-I}-\delta^{13} C_{C H_{4}-S O R-I}-\delta^{13} C_{C H_{4}-I I}+\delta^{13} C_{C H_{4}-S O R-I I}}
\end{aligned}
$$

Then, $f_{\text {ROC }}$ can be calculated from either equation (2) or (3).

2. Fraction of $\mathrm{CH}_{4}$ production from $\mathrm{RS}$ carbon $\left(\boldsymbol{f}_{\boldsymbol{R} S}\right)$. The $\delta^{13} \mathrm{C}$ values of the $\mathrm{CH}_{4}$ produced (or dissolved) in the two RS treatments are given by the following two mass balance equations:

$$
\begin{aligned}
& \delta^{13} C_{C H_{4}-I}= \\
& f_{R S} \delta^{13} C_{R S-I}+f_{S O M} \delta^{13} C_{S O M}+f_{R O C} \delta^{13} C_{R O C}+\Delta C H_{4} \\
& \delta^{13} C_{C H_{4}-I I}= \\
& f_{R S} \delta^{13} C_{R S-I I}+f_{S O M} \delta^{13} C_{S O M}+f_{R O C} \delta^{13} C_{R O C}+\Delta C H_{4}
\end{aligned}
$$

with $f_{\mathrm{RS}}, f_{\mathrm{SOM}}$ and $f_{\mathrm{ROC}}$ denote fractions of $\mathrm{CH}_{4}$ produced from $\mathrm{RS}$, SOM and ROC, respectively; $\delta^{13} \mathrm{C}_{\mathrm{RS}-\mathrm{I}}$ and $\delta^{13} \mathrm{C}_{\mathrm{RS}-\mathrm{II}}$ are $\delta^{13} \mathrm{C}$ of the rice straw carbon in treatment I (213.0\%) and II (474.7\%o), respectively; $\delta^{13} \mathrm{C}_{\text {SOM }}$ and $\delta^{13} \mathrm{C}_{\mathrm{ROC}}$ are $\delta^{13} \mathrm{C}$ of SOM

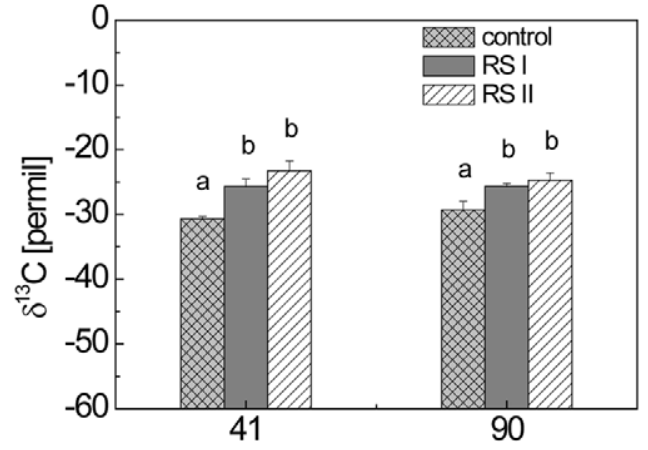

Days after transplanting

Figure 1. Values of $\delta^{13} \mathrm{C}$ of dried rice plants obtained from planted microcosms without (control) and with addition of ${ }^{13} \mathrm{C}$ labeled RS. RS I and RS II denote the two treatments, the $\delta^{13} \mathrm{C}$ of rice straw applied was $213.0 \%$ and $474.7 \%$ for RS I and RS II, respectively; means \pm standard deviation (SD) $(n=3)$. The differences between the treatments over time were examined using Duncan post hoc test of a one-way ANOVA. Different letters on the top of bars indicate significant difference $(P<0.05)$ between the data. doi:10.1371/journal.pone.0049073.g001

$\left(-25.8 \%\right.$ ) and of the plant biomass (Fig. 1), respectively; $\Delta \mathrm{CH}_{4}$ designates the overall isotopic fractionation factors involved in $\mathrm{CH}_{4}$ production from these organic matters, in case of dissolved $\mathrm{CH}_{4}$ also those involved in oxidation and transfer of $\mathrm{CH}_{4}$ from soil to the atmosphere.

Since the terms $f_{\text {SOM }} \delta^{13} \mathrm{C}_{\mathrm{SOM}}, f_{\mathrm{ROC}} \delta^{13} \mathrm{C}_{\mathrm{ROC}}$ and $\Delta \mathrm{CH}_{4}$ should be the same in treatment I and II, combination of equations (5) and (6) and solving for $f_{\mathrm{RS}}$ results in:

$$
f_{R S}=\frac{\delta^{13} C_{C H_{4}-I}-\delta^{13} C_{C_{4}-I I}}{\delta^{13} C_{R S-I}-\delta^{13} C_{R S-I I}}
$$

of which the $\delta^{13} \mathrm{C}$ can be determined experimentally. Here, $\delta^{13} \mathrm{C}_{\mathrm{CH} 4-\mathrm{I}}$ and $\delta^{13} \mathrm{C}_{\mathrm{CH} 4-\mathrm{II}}$ were determined experimentally, and $\delta^{13} \mathrm{C}_{\mathrm{RS}-\mathrm{I}}$ and $\delta^{13} \mathrm{C}_{\mathrm{RS}-\mathrm{II}}$ were mixtures of labeled and unlabelled RS, of which the $\delta^{13} \mathrm{G}$ were determined experimentally (see above). Finally, the fraction of $\mathrm{CH}_{4}$ production from SOM $\left(f_{\mathrm{SOM}}\right)$ can be calculated, since

$$
f_{R S}+f_{R O C}+f_{S O M}=1
$$

Analogous equations are valid for the fractions of $\mathrm{CO}_{2}$ produced from ROC, SOM and RS in rice field soil.

\section{Statistical analysis}

The significance of differences between treatments over time for various variables were determined by one-way analysis of variance (ANOVA) followed by multiple comparisons (Duncan post hoc test) using SPSS 13.0. To test the significance of the differences between contributions to produced and dissolved $\mathrm{CH}_{4}$ or $\mathrm{CO}_{2}$, two-tailed independent t-tests were applied using Microsoft Excel 2007.

\section{Results}

\section{Stable carbon signature of rice plants}

The $\delta^{13} \mathrm{C}$ of rice plants in the control and RS treatments were almost constant with time (Fig. 1). Rice plants in the RS treatments 
were enriched in $\delta^{13} \mathrm{C}$ by about 5\%o compared with the control. The $\delta^{13} \mathrm{C}$ of rice plants was consistently higher in treatment II than in treatment I, but the difference was not significant.

\section{Rates and $\delta^{13} \mathrm{C}_{\text {of }} \mathrm{CH}_{4}$ emitted from planted microcosms}

In the rice microcosms without addition of $\mathrm{RS}, \mathrm{CH}_{4}$ emission rates increased from the tillering stage (day 41) to the booting stage (day 55) and peaked at the flowering stage (day 70), then decreased again till the ripening stage (day 90) (Fig. 2A). Application of rice straw increased $\mathrm{CH}_{4}$ emission rates throughout the growth period, but particularly during tillering and booting stage (Fig. 2A). The $\delta^{13} \mathrm{C}$ of the emitted $\mathrm{CH}_{4}$ became gradually more negative during the cultivation period in all the treatments (Fig. 2B). The $\delta^{13} \mathrm{C}$ of $\mathrm{CH}_{4}$ was substantially higher in RS treatment II $>$ RS treatment I $>$ control, especially during the tillering stage (Fig. 2B).

\section{Concentrations and $\delta^{13} \mathrm{C}$ values of $\mathrm{CH}_{4}$ and $\mathrm{CO}_{2}$ dissolved in pore water}

Concentrations and $\delta^{13} \mathrm{C}$ values of dissolved $\mathrm{CH}_{4}$ and $\mathrm{CO}_{2}$ were similar in the pore water sampled from $3 \mathrm{~cm}$ and $9 \mathrm{~cm}$ soil depth. Therefore, only the data from the 9-cm soil layer are shown (Fig. 3, 4A and B). In the planted microcosms, $\mathrm{CH}_{4}$ concentrations increased steadily from the beginning until the ripening stage. Application of rice straw resulted in elevated $\mathrm{CH}_{4}$ concentrations in the beginning but subsequently became similar to the control (Fig. 3A). The $\delta^{13} \mathrm{C}$ values of the $\mathrm{CH}_{4}$ dissolved in planted and unplanted microcosms were similar with each other in both RS treatments at tillering stage (Fig. 4A). However, while $\delta^{13} \mathrm{C}$ values decreased with time in the planted microcosms, they did not decrease much in the unplanted microcosms. The $\delta^{13} \mathrm{C}$ of the dissolved $\mathrm{CH}_{4}$ was consistently higher (less negative) in RS treatment II $>$ RS treatment I > control for both planted and unplanted microcosms (Fig. 4A). The $\delta^{13} \mathrm{C}$ values of the dissolved $\mathrm{CH}_{4}$ in planted microcosms (Fig. 4A) were similar to those of the emitted $\mathrm{CH}_{4}$ (Fig. 2B).

In the planted microcosms, dissolved $\mathrm{CO}_{2}$ concentrations were between 4.0 and $5.5 \mathrm{mM}$ independently of the treatment and the vegetation period (Fig. 3B). The $\delta^{13} \mathrm{C}$ of the dissolved $\mathrm{CO}_{2}$ exhibited a temporal pattern similar to that of $\mathrm{CH}_{4}$ and was again consistently higher (less negative) in RS treatment II $>$ RS treatment $\mathrm{I}>$ control (Fig. $4 \mathrm{~B}$ ). However, $\delta^{13} \mathrm{C}$ of dissolved $\mathrm{CO}_{2}$ was in general higher (less negative) than that of $\mathrm{CH}_{4}$.
4. Rates and $\delta^{13} \mathrm{C}_{\text {of }} \mathrm{CH}_{4}$ and $\mathrm{CO}_{2}$ produced in planted and unplanted microcosms

At each time of sampling, soil cores were collected from microcosms with and without rice plants, in order to determine the rates and the $\delta^{13} \mathrm{C}$ of the $\mathrm{CH}_{4}$ and $\mathrm{CO}_{2}$ produced. Depending on the microcosm tested, $\mathrm{CH}_{4}$ and $\mathrm{CO}_{2}$ were produced from ROC (planted microcosms), SOM (all microcosms) and RS (RS-treated microcosms). In the planted control without RS treatment, $\mathrm{CH}_{4}$ production rates increased steadily during the vegetation period (Fig. 5A). However, treatment with RS resulted in further increase of $\mathrm{CH}_{4}$ production rates. In the unplanted microcosms, $\mathrm{CH}_{4}$ production rates were also enhanced by RS treatments but were lower than in the planted microcosms with RS treatment. The $\delta{ }^{13} \mathrm{C}$ of produced $\mathrm{CH}_{4}$ was similar in the planted and unplanted control microcosms without RS (Fig. 4C). Treatment with RS resulted in increase of $\delta^{13} \mathrm{C}$ values of produced $\mathrm{CH}_{4}$, which was higher in treatment II than treatment I. However, the increase was less in the planted than in the unplanted microcosms (Fig. 4C).

The rates of $\mathrm{CO}_{2}$ production were constant over the vegetation period in the planted microcosms and were similar for the treatments with and without RS, but were at least twice as high in planted as in unplanted microcosms (Fig. 5B). The $\delta^{13} \mathrm{C}$ values of $\mathrm{CO}_{2}$ exhibited a similar pattern with respect to vegetation period and treatment as that of $\mathrm{CH}_{4}$, but the values were generally higher (Fig. 4D).

\section{Partitioning $\mathrm{CH}_{4}$ and $\mathrm{CO}_{2}$ produced in rice microcosms}

For calculation of $f_{\text {ROC }}$, first of all the $\delta^{13} \mathrm{C}$ of the $\mathrm{CH}_{4}$ and $\mathrm{CO}_{2}$ produced from ROC had to be determined. The data, which were calculated using eq. (4), are shown in Table 1. The $\delta^{13} \mathrm{C}$ of $\mathrm{CH}_{4}$ produced from ROC was about $-60 \%$ on average (range of -67 to $-49 \%$ ) during the whole vegetation period, though fluctuations on individual sampling dates, at tillering stage in particular, were rather high (Table 1). The $\delta^{13} \mathrm{C}$ values of $\mathrm{CO}_{2}$ produced from ROC were about $-31 \%$ at tillering stage and increased to around $-11 \%$ to $-4 \%$ subsequently (Table 1 ). Values of $f_{\text {ROC }}$ were then calculated using eq. (2) and (3). Both equations gave similar values, but those obtained with eq. (2) showed higher standard deviations than those obtained with eq. (3). Only the latter values are shown in Fig. 6 and 7. ROC was found to make a major contribution (41-63\%) to $\mathrm{CH}_{4}$ production over the entire vegetation period (Fig. 6A). For $\mathrm{CO}_{2}$ production, ROG had even a higher importance (43-76\%) (Fig. 7A).
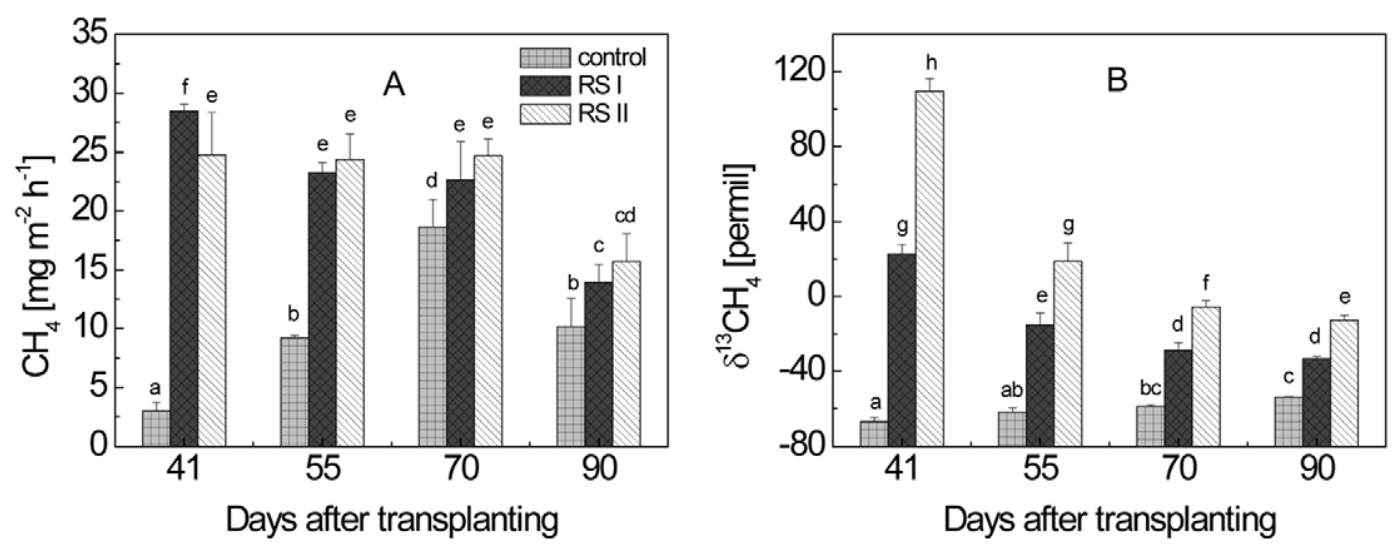

Figure 2. Seasonal change of (A) $\mathrm{CH}_{4}$ emission rates and (B) $\delta^{13} \mathrm{C}_{\text {of }} \mathrm{CH}_{4}$ emitted in planted microcosms with and without treatment with ${ }^{13} \mathbf{C}$-labeled RS; means \pm SD $(\mathbf{n}=\mathbf{4})$. The differences between the treatments over time were examined using Duncan post hoc test of a oneway ANOVA. Different letters on the top of bars indicate significant difference $(P<0.05)$ between the data. doi:10.1371/journal.pone.0049073.g002 

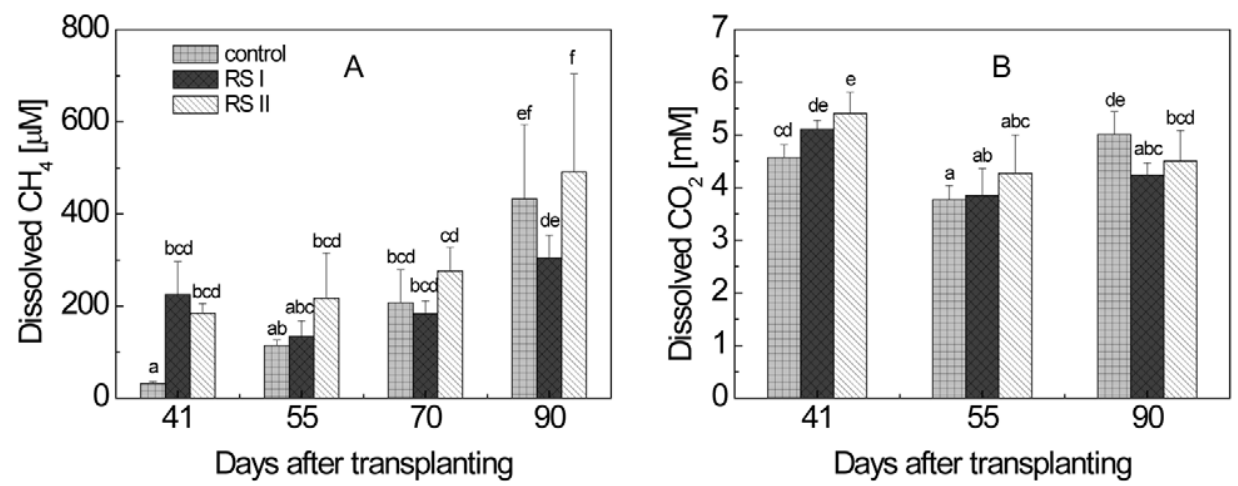

Figure 3. Temporal change of the concentrations of dissolved (A) $\mathrm{CH}_{4}$ and (B) $\mathrm{CO}_{2}$ in planted microcosms with and without addition of ${ }^{13}$ C-labeled RS; means \pm SD $(\mathbf{n}=\mathbf{4})$. The differences between the treatments over time were examined using Duncan post hoc test of a oneway ANOVA. Different letters on the top of bars indicate significant difference $(P<0.05)$ between the data.

doi:10.1371/journal.pone.0049073.g003

The fractions of $\mathrm{CH}_{4}$ and $\mathrm{CO}_{2}$ produced from $\mathrm{RS}\left(f_{\mathrm{RS}}\right)$ were calculated using eq. (7). Values of $\delta^{13} \mathrm{C}$ were obtained from the $\mathrm{CH}_{4}$ (Fig. 4C) and $\mathrm{CO}_{2}$ (Fig. 4D) produced in soil samples from planted microcosms. Values of $f_{\mathrm{RS}}$ were determined to be in a range of $12-24 \%$ for $\mathrm{CH}_{4}$ production (Fig. 6B) and $11-31 \%$ for $\mathrm{CO}_{2}$ production (Fig. 7B).

Finally, $f_{\text {SOM }}$ was calculated by difference to $f_{\text {ROC }}$ and $f_{\mathrm{RS}}$, being in a range of $23-35 \%$ of $\mathrm{CH}_{4}$ (Fig. 6C) and $13-26 \%$ of $\mathrm{CO}_{2}$ production in soil from planted and straw-treated microcosms (Fig. 7C).
6. Partitioning $\mathrm{CH}_{4}$ and $\mathrm{CO}_{2}$ dissolved in rice microcosms Similarly as for the production of $\mathrm{CH}_{4}$ and $\mathrm{CO}_{2}$ (see above), the gases dissolved in the rice microcosms were also used for determination of the partitioning of their origin from ROC, RS, and SOM using the equations described above. In this case, values of $\delta^{13} \mathrm{C}$ were from the $\mathrm{CH}_{4}$ and $\mathrm{CO}_{2}$ dissolved in pore water of planted and unplanted microcosms (Fig. 4A and B). The $\delta^{13} \mathrm{C}$ of $\mathrm{CH}_{4}$ derived from $\mathrm{ROG}$ was $-30 \%$ at tillering stage when calculated with $\delta^{13} \mathrm{C}$ of $\mathrm{CH}_{4}$ in pore water (Table 2), substantially more positive than that calculated with $\delta^{13} \mathrm{C}$ of produced $\mathrm{CH}_{4}$ (Table 1). The resulting $f_{\text {ROC }}$ for $\mathrm{CH}_{4}$ was only $13 \%$ (Fig. 6A). In
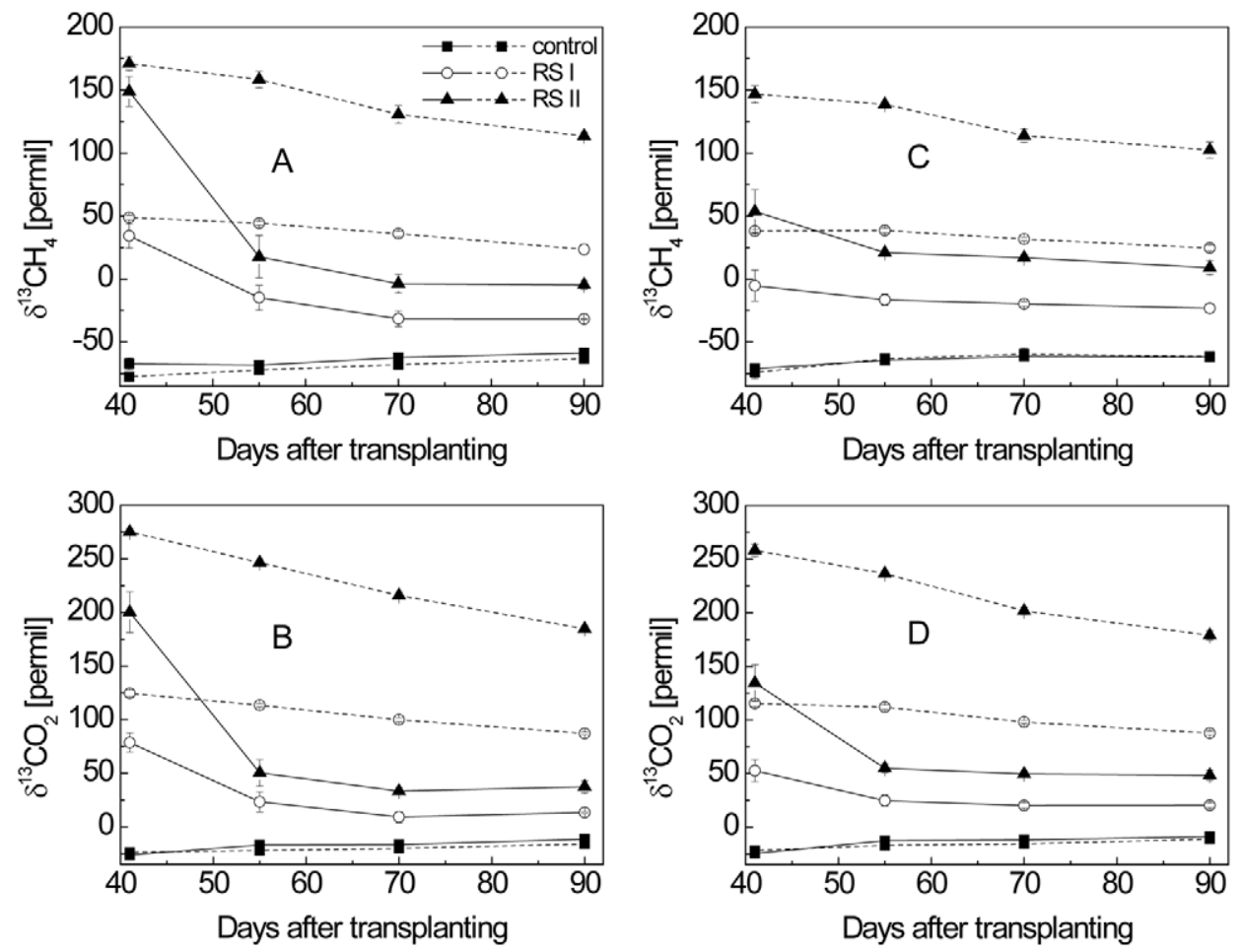

Figure 4. $\delta^{13} \mathrm{C}$ of (A) $\mathrm{CH}_{4}$ and (B) $\mathrm{CO}_{2}$ dissolved in microcosms with and without $\mathrm{RS}$ application; $\delta^{13} \mathrm{C}$ of (C) $\mathrm{CH}_{4}$ and (D) $\mathrm{CO}_{2}$ produced in microcosms with and without RS application. Solid line indicated planted microcosms, dashed lines unplanted microcosms; means \pm SD $(n=4)$.

doi:10.1371/journal.pone.0049073.g004 

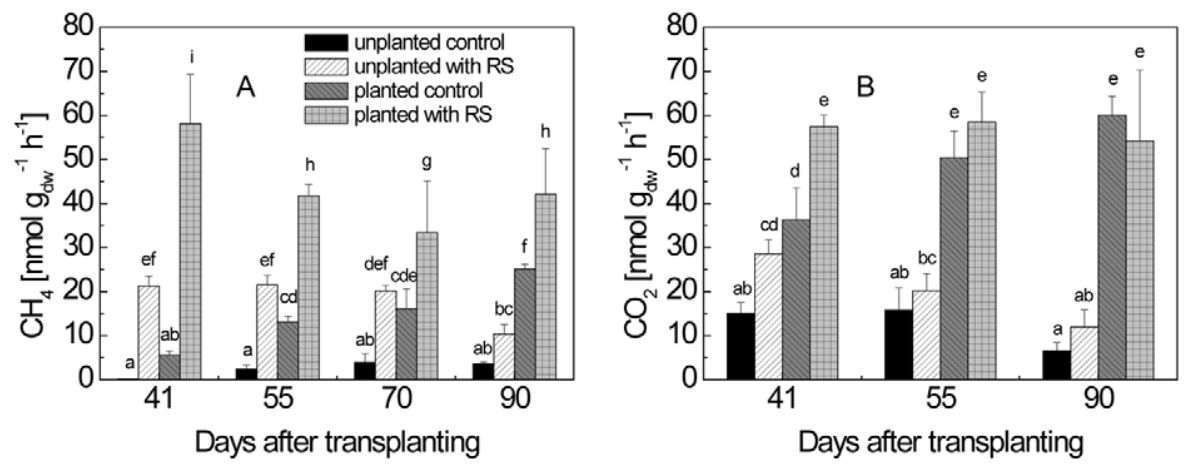

Figure 5. Production rates of (A) $\mathrm{CH}_{4}$ and (B) $\mathrm{CO}_{2}$ in planted and unplanted microcosms with and without $\mathrm{RS}$ application; means \pm SD $(\mathbf{n}=\mathbf{4})$. The differences between the treatments over time were examined using Duncan post hoc test of a one-way ANOVA. Different letters on the top of bars indicate significant difference $(P<0.05)$ between the data. doi:10.1371/journal.pone.0049073.g005

contrast, the relative contribution of $\mathrm{RS}\left(f_{\mathrm{RS}}\right)$ to $\mathrm{CH}_{4}$ dissolved was significantly higher than that for $\mathrm{CH}_{4}$ produced at the tillering stage (Fig. 6B). However, the relative contributions of each carbon source to dissolved and produced $\mathrm{CH}_{4}$ were nearly the same at later season (Fig. 6). For $\mathrm{CO}_{2}$, the $\delta^{13} \mathrm{C}$ of $\mathrm{CO}_{2}$ derived from ROC was $-49 \%$ at tillering stage, more negative than that calculated with $\delta^{13} \mathrm{C}$ of produced $\mathrm{CO}_{2}(-31 \%)$, but there was no significant difference between the relative contributions of each carbon source to dissolved and produced $\mathrm{CO}_{2}$ (Fig. 7).

\section{Discussion}

\section{Partitioning of methane production}

Our study comprehensively determined the partitioning of $\mathrm{CH}_{4}$ and $\mathrm{CO}_{2}$ production in a rice ecosystem considering all three major carbon sources (i.e., ROG, RS, SOM). In planted and straw-treated rice microcosms, more than $60 \%$ of the $\mathrm{CH}_{4}$ was produced from root organic carbon, except on the first sampling date (tillering stage) when it was $41 \%$. Thus, plant photosynthesis was the most important driver of $\mathrm{CH}_{4}$ production. The same was the case for $\mathrm{CO}_{2}$ production. The results are consistent with the observation that $\mathrm{CH}_{4}$ and $\mathrm{CO}_{2}$ production rates were at least twice as high in microcosms with than without rice plants (Fig. 5A and $5 \mathrm{~B})$. At the same time, the substantial lower $\delta^{13} \mathrm{C}$ of $\mathrm{CH}_{4}$ and $\mathrm{CO}_{2}$ produced in planted versus unplanted microcosms also indicated that ROC-derived $\mathrm{CH}_{4}$ and $\mathrm{CO}_{2}$ production diluted the $\mathrm{CH}_{4}$ and $\mathrm{CO}_{2}$ produced from labeled rice straw (Fig. 4C and 4D). Our results are consistent with two earlier experiments reporting $40-60 \%$ of the $\mathrm{CH}_{4}$ production being due to plant derived carbon. These experiments were based on pulse-labeling and FACE techniques [11,13], which potentially influence carbon flux partitioning in a different way than our approach. For instance,

Table 1. $\delta^{13} \mathrm{C}$ values of $\mathrm{CH}_{4}$ and $\mathrm{CO}_{2}$ derived from $\mathrm{ROC}$ in planted rice microcosms with RS application.

\begin{tabular}{lllll}
\hline & & & \\
\hline $\begin{array}{l}\text { Days after } \\
\text { transplanting }\end{array}$ & $\mathbf{4 1}$ & $\mathbf{5 5}$ & $\mathbf{7 0}$ & $\mathbf{9 0}$ \\
\hline$\delta^{13} \mathrm{C}_{\mathrm{CH} 4-\mathrm{ROC}}$ & $-67.4 \pm 66.7$ & $-49.4 \pm 14.2$ & $-61.3 \pm 10.2$ & $-57.2 \pm 17.4$ \\
$\delta^{13} \mathrm{C}_{\mathrm{CO}-\mathrm{ROC}}$ & $-31.3 \pm 65.1$ & $-3.6 \pm 14.6$ & $-10.7 \pm 8.8$ & $-9.7 \pm 10.6$ \\
\hline $\begin{array}{l}\text { The values were calculated using } \delta^{13} \mathrm{C} \text { of } \mathrm{CH}_{4} \text { and } \mathrm{CO}_{2} \text { produced in rice field } \\
\text { soil; means } \pm \mathrm{SD}(\mathrm{n}=4) . \\
\text { doi:10.1371/journal.pone.0049073.t001 }\end{array}$ & &
\end{tabular}

pulse-labeling may only account for part of the plant-derived carbon flux and FACE treatment may stimulate carbon flux $[13,14]$. Nevertheless, the determined relative contribution of plant derived carbon to production of $\mathrm{CH}_{4}$ and $\mathrm{CO}_{2}$ was rather similar despite the different approaches. Hence, the results that plant-derived carbon is the most important carbon source for $\mathrm{CH}_{4}$ production in flooded rice fields is a rather robust finding.

In contrast to ROC, straw contributed only about $20 \%$ to $\mathrm{CH}_{4}$ production. A similar low percentage has previously been found in Japanese rice soil microcosms after 50 days of incubation [4]. Immediately after application of the straw, however, its contribution to $\mathrm{CH}_{4}$ production and emission reached almost $100 \%$ [4]. This was likely also the case in our experiments. This conclusion is supported by the following observations: (1) On day $41, \delta^{13} \mathrm{G}$ of the produced $\mathrm{CH}_{4}$ was $<150 \%$ albeit the applied rice straw carbon had a $\delta^{13} \mathrm{C}$ of $474.7 \%$ (Fig. 4C). The difference is much more than theoretically possible from isotope discrimination during methanogenesis. Therefore, we have to assume that the $\mathrm{CH}_{4}$ produced immediately after straw application had a much higher $\delta^{13} \mathrm{C}$ as it was derived from straw to a large extent. (2) The analogous observation was made with the produced $\mathrm{CO}_{2}$ (Fig. 4D), although isotope discrimination is much smaller for production of $\mathrm{CO}_{2}$ than of $\mathrm{CH}_{4}$. (3) Still after day $40, \delta^{13} \mathrm{C}$ of the produced $\mathrm{CH}_{4}$ and $\mathrm{CO}_{2}$ tended to decrease with vegetation time. Hence, we conclude that contribution of decomposition of straw to $\mathrm{CH}_{4}$ production was very high after straw application and then progressively decreased as the carbon compounds of the straw became increasingly less decomposable. Future studies should further refine the seasonal change in flux partitioning. This will help improving the predictions of $\mathrm{CH}_{4}$ emission rates from rice fields by process-based modeling.

\section{Contribution of different carbon sources to the dissolved $\mathrm{CH}_{4}$ and $\mathrm{CO}_{2}$}

Previous studies reported that $\delta^{13} \mathrm{C}$ values of pore water $\mathrm{CH}_{4}$ and emitted $\mathrm{CH}_{4}$ were relatively poor proxies for those of produced $\mathrm{CH}_{4}[32,33]$. This assessment is plausible, since in rice field soil pore water $\mathrm{CH}_{4}$ and emitted $\mathrm{CH}_{4}$ are not only affected by $\mathrm{CH}_{4}$ production, but also by $\mathrm{CH}_{4}$ oxidation [34-36] and $\mathrm{CH}_{4}$ transport [37-39], which all undergo carbon isotopic fractionation. Therefore, we primarily used the $\mathrm{CH}_{4}$ produced in soil samples for determining flux partitioning. However, we found that not only the data of the produced $\mathrm{CH}_{4}$ but also of the dissolved $\mathrm{CH}_{4}$ allowed determination of flux partitioning and resulted in similar values. Thus, more than $60 \%$ of the $\mathrm{CH}_{4}$ and $\mathrm{CO}_{2}$ 

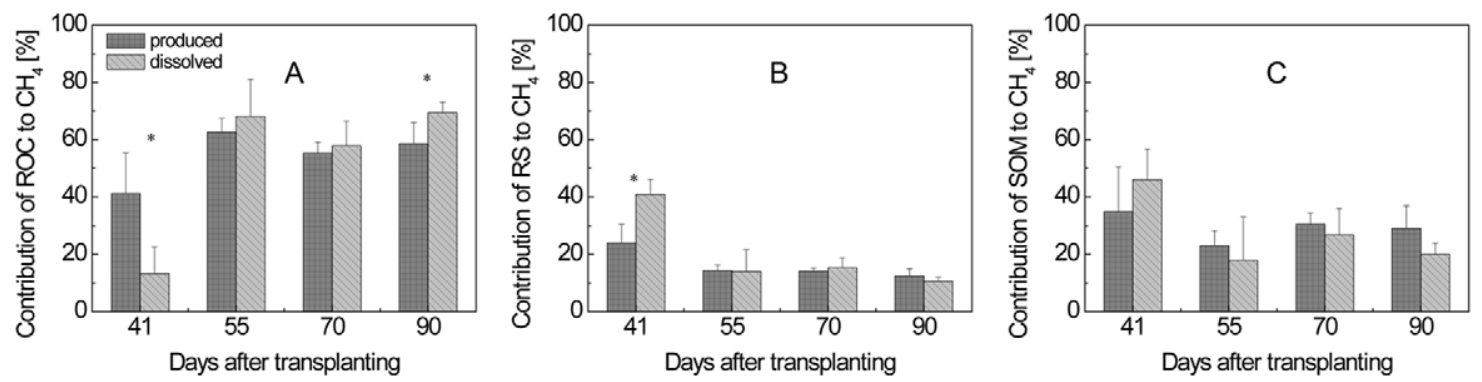

Figure 6. Percentage contribution of (A) ROC, (B) SOM and (C) RS to produced and dissolved $\mathrm{CH}_{4}$ in planted microcosms with RS treatment; means \pm SD $(\mathbf{n}=4)$. The differences between contributions to produced and dissolved $\mathrm{CH}_{4}$ were tested by two-tailed independent $\mathrm{t}$ tests, indicated by ${ }^{*}$ when $P<0.05$.

doi:10.1371/journal.pone.0049073.g006

dissolved in soil pore water were derived from root organic carbon after tillering stage, nearly the same as for produced $\mathrm{CH}_{4}$ and $\mathrm{CO}_{2}$ (Fig. 6 and 7).

At tillering stage, however, the relative contribution of ROC to the dissolved $\mathrm{CH}_{4}$ was significantly lower and that of RS significantly higher when compared to the contribution to the produced $\mathrm{CH}_{4}$. The difference was probably due to the gas transport limitation of rice plants at the early vegetative stage $[32,40]$. The residence time of $\mathrm{CH}_{4}$ in pore water at tillering stage can amount to several days. Therefore, at day 41 the pore water was probably still highly enriched in ${ }^{13} \mathrm{CH}_{4}$ which had been produced from RS at earlier time. This conclusion is consistent with the substantially higher $\delta^{13} \mathrm{C}$ values of the dissolved $\mathrm{CH}_{4}$ than those of the produced $\mathrm{CH}_{4}$ at day 41 (Fig $4 \mathrm{~A}$ and $4 \mathrm{C}$ ). As a result, the relative contribution of $\mathrm{RS}$ to dissolved $\mathrm{CH}_{4}$ was higher than to produced $\mathrm{CH}_{4}$ at day 41 and that of ROC was lower (Fig. 6B).

In contrast, at later growth season, the residence time of $\mathrm{CH}_{4}$ in pore water of planted soil was much shorter (several hours) [32], this was consistent with the rapid decrease of $\delta^{13} \mathrm{C}$ values of dissolved $\mathrm{CH}_{4}$ and $\mathrm{CO}_{2}$ after tillering stage. Furthermore, the $\delta^{13} \mathrm{C}$ values of dissolved and produced $\mathrm{CH}_{4}$ were similar with each other after the tillering stage (Fig. $4 \mathrm{~A}$ and $4 \mathrm{C}$ ). Therefore, the relative contributions of each carbon source to dissolved and produced $\mathrm{CH}_{4}$ were similar to each other (Fig. 6). This suggested that pore water $\mathrm{CH}_{4}$ could be used as a proxy for produced $\mathrm{CH}_{4}$ and could be suitable for partitioning the $\mathrm{CH}_{4}$ production after tillering stage.

\section{Stable carbon isotope fractionation during $\mathrm{CH}_{4}$ production from $\mathrm{ROC}$}

The $\delta^{13} \mathrm{C}$ of the $\mathrm{CH}_{4}$ produced from $\mathrm{ROC}\left(\delta^{13} \mathrm{C}_{\mathrm{CH} 4-\mathrm{ROC}}\right)$ were in a range of $-67 \%$ o to $-49 \%$. These values are similar to $\delta^{13} \mathrm{C}_{\mathrm{CH} 4}$ values observed in rice field soil or in incubations of soil slurries [23,33]. Theoretically the value of $\delta^{13} \mathrm{C}_{\mathrm{CH}}$-ROC should be equal to the $\delta^{13} \mathrm{C}$ of ROC plus the overall isotopic enrichment factor $\left(\varepsilon_{\mathrm{ROC}, \mathrm{CH} 4}\right)$ for the conversion of $\mathrm{ROC}$ to $\mathrm{CH}_{4}$. The $\delta^{13} \mathrm{C}_{\mathrm{ROC}}$ should be similar to the $\delta^{13} \mathrm{C}$ of the rice plant biomass (Fig. 1). Using these values and the $\delta^{13} \mathrm{C}_{\mathrm{CH} 4-\mathrm{ROC}}$, the overall enrichment factor $\varepsilon_{\mathrm{ROC}, \mathrm{CH} 4}$ was in a range of about $-24 \%$ to $-42 \%$. This is a rather large range, but has been observed before (about $-20 \%$ to $-75 \%$ ) during anaerobic decomposition of straw in paddy soil [41] or anoxic incubations of rice roots [42]. The overall enrichment factor $\varepsilon_{\mathrm{ROC}, \mathrm{CH} 4}$ is composed of (1) the enrichment factors involved in the conversion of ROC to the methanogenic substrates (i.e., acetate and $\mathrm{H}_{2} / \mathrm{CO}_{2}$ ) and (2) in the enrichment factors involved in the conversion of the methanogenic substrates to $\mathrm{CH}_{4}$. The latter enrichment factors are the larger ones, in particular those involved in the production of $\mathrm{CH}_{4}$ from $\mathrm{H}_{2} / \mathrm{CO}_{2}$ [23,43]. Whereas acetoclastic methanogenesis has relatively moderate enrichment factors $(-10 \%$ to $-25 \%)$, those of hydrogenotrophic methanogenesis are often very large $(-25 \%$ to $-90 \%$ ) [22]. Our data suggest that $\mathrm{CH}_{4}$ production from $\mathrm{ROC}$ is dominated by hydrogenotrophic methanogenesis, which is consistent with earlier observations studying $\mathrm{CH}_{4}$ production on rice roots $[42,44,45]$.

The $\delta^{13} \mathrm{C}$ of the $\mathrm{CO}_{2}$ produced from root organic carbon was in a range of $-31 \%$ to $-4 \%$ (Table 1 ). The overall isotopic
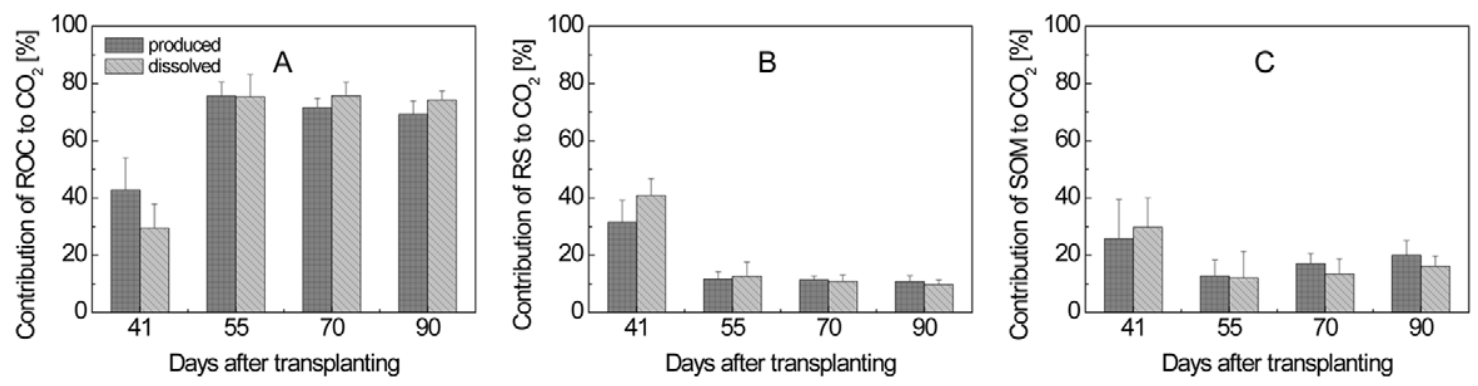

Figure 7. Percentage contribution of (A) ROC, (B) SOM and (C) RS to produced and dissolved $\mathrm{CO}_{2}$ in planted microcosms with RS treatment; means \pm SD $(\mathbf{n}=\mathbf{4})$. The differences between contributions to produced and dissolved $\mathrm{CH}_{4}$ were tested by two-tailed independent $\mathrm{t}$ tests, indicated by ${ }^{*}$ when $P<0.05$.

doi:10.1371/journal.pone.0049073.g007 
Table 2. $\delta^{13} \mathrm{C}$ values of $\mathrm{CH}_{4}$ and $\mathrm{CO}_{2}$ derived from $\mathrm{ROC}$ in planted rice microcosms with RS application.

\begin{tabular}{lllll}
\hline & & & & \\
\hline $\begin{array}{l}\text { Days after } \\
\text { transplanting }\end{array}$ & $\mathbf{4 1}$ & $\mathbf{5 5}$ & $\mathbf{7 0}$ & $\mathbf{9 0}$ \\
\hline$\delta^{13} \mathrm{C}_{\mathrm{CH} 4-\mathrm{ROC}}$ & $-29.9 \pm 95.2$ & $-38.7 \pm 25.4$ & $-72.2 \pm 28$ & $-51.0 \pm 7.6$ \\
$\delta^{13} \mathrm{C}_{\mathrm{CO}-\mathrm{ROC}}$ & $-49.2 \pm 81.1$ & $-3.8 \pm 22$ & $-14.2 \pm 14.2$ & $-8.5 \pm 6.1$ \\
\hline $\begin{array}{l}\text { The values were calculated using } \\
\left.\text { means } \pm{ }^{13} \mathrm{C} \text { of } \mathrm{CH}_{4} \text { and } \mathrm{n}=4\right) .\end{array}$ \\
$\begin{array}{l}\text { doi:10.1371/journal.pone.0049073.t002 } \\
\text { dissolved in pore water; }\end{array}$
\end{tabular}

enrichment factors involved in $\mathrm{CO}_{2}$ production from organic matter were thus about $-6 \%$ to $+21 \%$. These enrichment factors are much smaller than those involved in $\mathrm{CH}_{4}$ production. Nevertheless, the range is similarly large, which may be due to carbon isotopic fractionation during $\mathrm{CO}_{2}$ consumption by hydrogenotrophic methanogenesis [23] and also during reactions between gaseous $\mathrm{CO}_{2}$ and bicarbonate/carbonate [46].

\section{Practical considerations}

Our study demonstrated the possibility to determine the partitioning of $\mathrm{CH}_{4}$ and $\mathrm{CO}_{2}$ flux from degradation of straw, soil organic matter, and plant root-derived carbon, by treating soil with ${ }^{13} \mathrm{C}$-labeled rice straw. The procedure is more practical than labeling of the rice plants with ${ }^{13} \mathrm{CO}_{2}$ that requires cumbersome incubation techniques or expensive FACE treatment. For calculation of $f_{\text {ROC }}$, it was important that the $\delta^{13} \mathrm{C}$ of the two RS applications were sufficiently different from each other, and in addition were sufficiently different from the $\delta^{13} \mathrm{C}$ of both ROC and SOM. This was achieved by two RS treatments using the same amount of RS but ${ }^{13} \mathrm{C}$-labeled to different extent. As a result, the $\delta^{13} \mathrm{C}$ of emitted $\mathrm{CH}_{4}$ (Fig. 2B), $\delta^{13} \mathrm{C}$ of dissolved and produced $\mathrm{CH}_{4}$ and $\mathrm{CO}_{2}$ (Fig. 4) were substantially higher than the control

\section{References}

1. Cai ZC, Tsuruta H, Minami K (2000) Methane emission from rice fields in China: Measurements and influencing factors. Journal of Geophysical ResearchAtmospheres 105: 17231-17242.

2. Lelieveld J, Crutzen PJ, Dentener FJ (1998) Changing concentration, lifetime and climate forcing of atmospheric methane. Tellus Series B-Chemical and Physical Meteorology 50: 128-150.

3. Kimura M, Murase J, Lu YH (2004) Carbon cycling in rice field ecosystems in the context of input, decomposition and translocation of organic materials and the fates of their end products $\left(\mathrm{CO}_{2}\right.$ and $\left.\mathrm{CH}_{4}\right)$. Soil Biology \& Biochemistry 36 : 1399-1416.

4. Watanabe A, Takeda T, Kimura M (1999) Evaluation of origins of $\mathrm{CH}_{4}$ carbon emitted from rice paddies. Journal of Geophysical Research 104: 23623-23629.

5. Sass RL, Fisher FM, Harcombe PA, Turner FT (1991) Mitigation of methane emissions from rice fields: Possible adverse effects of incorporated rice straw. Global Biogeochemical Cycles 5: 275-287.

6. Schütz H, Holzapfel-Pschorn A, Conrad R, Rennenberg H, Seiler W (1989) A 3 -year continuous record on the influence of daytime, season, and fertilizer treatment on methane emission rates from an Italian rice paddy. Journal of Geophysical Research 94: 16405-16416.

7. Yagi K, Minami K (1990) Effect of organic matter application on methane emission from some Japanese paddy fields. Soil Science and Plant Nutrition 36: $599-610$.

8. Fumoto T, Kobayashi K, Li C, Yagi K, Hasegawa T (2008) Revising a processbased biogeochemistry model (DNDC) to simulate methane emission from rice paddy fields under various residue management and fertilizer regimes. Global Change Biology 14: 382-402.

9. Li C, Mosier A, Wassmann R, Cai Z, Zheng X, et al. (2004) Modeling greenhouse gas emissions from rice-based production systems: Sensitivity and upscaling. Global Biogeochemical Cycles 18: GB1043.

10. Dannenberg S, Conrad R (1999) Effect of rice plants on methane production and rhizospheric metabolism in paddy soil. Biogeochemistry 45: 53-71.

11. Minoda T, Kimura M, Wada E (1996) Photosynthates as dominant source of $\mathrm{CH}_{4}$ and $\mathrm{CO}_{2}$ in soil water and $\mathrm{CH}_{4}$ emitted to the atmosphere from paddy fields. Journal of Geophysical Research 101: 21091-21097. without RS, and of course they were always higher in treatment II than treatment I.

Calculation of $f_{\mathrm{RS}}$ was simply achieved by using the $\delta^{13} \mathrm{C}$ values of the applied RS and the $\mathrm{CH}_{4}$ derived from the two RS treatments (Eq. 7) assuming that ROC was not differently affected by the two RS treatments. This assumption was in agreement with the observation that the ${ }^{13} \mathrm{C}$ values of the rice plants in the two RS treatments were not significantly different (Fig 1). Notably, these values were significantly higher than those in the control microcosms without RS, probably because some of the RS carbon was assimilated (probably via $\mathrm{CO}_{2}$ ) by the plants $[20,21]$. However, the difference was only a few permil and did not prevent computation of flux partitioning, since the difference to the $\delta^{13} \mathrm{C}$ of the labeled RS was quite large.

In summary, application of labeled RS may be a convenient technique to determine flux partitioning in rice fields on a routine basis. The determination requires in total three planted field plots and three unplanted ones, i.e., two RS treatments and one untreated control, everything with appropriate replication. Technical installation is not required. Hence, it should be feasible to increase the data basis on the partitioning of $\mathrm{CH}_{4}$ production from ROC, RS and SOM on a regional and seasonal scale. This will help improving process-based modeling of $\mathrm{CH}_{4}$ emission from rice fields.

\section{Acknowledgments}

We thank P. Claus and M. Klose for laboratory technical assistance, R. Angel for help in statistical analysis.

\section{Author Contributions}

Conceived and designed the experiments: QY RG. Performed the experiments: QY. Analyzed the data: QY RC. Contributed reagents/ materials/analysis tools: JP. Wrote the paper: QY RC.

12. Watanabe A, Machida N, Takahashi K, Kitamura S, Kimura M (2004) Flow of photosynthesized carbon from rice plants into the paddy soil ecosystem at different stages of rice growth. Plant and Soil 258: 151-160.

13. Tokida T, Adachi M, Cheng WG, Nakajima Y, Fumoto T, et al. (2011) Methane and soil $\mathrm{CO}_{2}$ production from current-season photosynthates in a rice paddy exposed to elevated $\mathrm{CO}_{2}$ concentration and soil temperature. Global Change Biology 17: 3327-3337.

14. Meharg AA (1994) A critical-review of labeling techniques used to quantify rhizosphere carbon-flow. Plant and Soil 166: 55-62.

15. Ostle N, Briones MJI, Ineson P, Cole L, Staddon P, et al. (2007) Isotopic detection of recent photosynthate carbon flow into grassland rhizosphere fauna. Soil Biology \& Biochemistry 39: 768-777.

16. Denef K, Bubenheim H, Lenhart K, Vermeulen J, Van Cleemput O, et al. (2007) Community shifts and carbon translocation within metabolically-active rhizosphere microorganisms in grasslands under elevated $\mathrm{CO}_{2}$. Biogeosciences 4: 769-779.

17. Tokida T, Fumoto T, Cheng W, Matsunami T, Adachi M, et al. (2010) Effects of free-air $\mathrm{CO}_{2}$ enrichment (FACE) and soil warming on $\mathrm{CH}_{4}$ emission from a rice paddy field: impact assessment and stoichiometric evaluation. Biogeosciences 7: 2639-2653.

18. Carney KM, Hungate BA, Drake BG, Megonigal JP (2007) Altered soil microbial community at elevated $\mathrm{CO}_{2}$ leads to loss of soil carbon. Proceedings of the National Academy of Sciences of the United States of America 104: 49904995 .

19. Langley JA, McKinley DC, Wolf AA, Hungate BA, Drake BG, et al. (2009) Priming depletes soil carbon and releases nitrogen in a scrub-oak ecosystem exposed to elevated $\mathrm{CO}_{2}$. Soil Biology \& Biochemistry 41: 54-60.

20. Chidthaisong A, Watanabe I (1997) Methane formation and emission from flooded rice soil incorporated with ${ }^{13} \mathrm{C}$-labeled rice straw. Soil Biology \& Biochemistry 29: 1173-1181.

21. Watanabe A, Yoshida M, Kimura M (1998) Contribution of rice straw carbon to $\mathrm{CH}_{4}$ emission from rice paddies using ${ }^{13} \mathrm{C}$-enriched rice straw. Journal of Geophysical Research 103: 8237-8242. 
22. Conrad R (2005) Quantification of methanogenic pathways using stable carbon isotopic signatures: a review and a proposal. Organic Geochemistry 36: 739 752.

23. Penning H, Conrad R (2007) Quantification of carbon flow from stable isotope fractionation in rice field soils with different organic matter content. Organic Geochemistry 38: 2058-2069.

24. Conrad R, Noll M, Claus P, Klose M, Bastos WR, et al. (2011) Stable carbon isotope discrimination and microbiology of methane formation in tropical anoxic lake sediments. Biogeosciences 8: 795-814.

25. Whiticar MJ, Faber E, Schoell M (1986) Biogenic methane formation in marine and fresh-water environments: $\mathrm{CO}_{2}$ reduction vs acetate fermentation - isotope evidence. Geochimica Et Cosmochimica Acta 50: 693-709.

26. Oleary MH (1981) Carbon isotope fractionation in plants. Phytochemistry 20: 553-567.

27. Krüger M, Frenzel P, Conrad R (2001) Microbial processes influencing methane emission from rice fields. Global Change Biology 7: 49-63.

28. Holzapfel-Pschorn A, Seiler W (1986) Methane emission during a cultivation period from an Italian rice paddy. Journal of Geophysical Research 91: 1180311814.

29. Bodelier PLE, Hahn AP, Arth IR, Frenzel P (2000) Effects of ammonium-based fertilisation on microbial processes involved in methane emission from soils planted with rice. Biogeochemistry 51: 225-257.

30. Brand WA (1995) Precon: a fully automated interface for the pre-GC concentration of trace gases in air for isotopic analysis. Isotopes in Environmental and Health Studies 31: 277-284.

31. Brand WA (1996) High precision isotope ratio monitoring techniques in mass spectrometry. Journal of Mass Spectrometry 31: 225-235.

32. Conrad R, Klose M (2005) Effect of potassium phosphate fertilization on production and emission of methane and its ${ }^{13} \mathrm{C}$-stable isotope composition. Soil Biology \& Biochemistry 37: 2099-2108.

33. Krüger M, Eller G, Conrad R, Frenzel P (2002) Seasonal variation in pathways of $\mathrm{CH}_{4}$ production and in $\mathrm{CH}_{4}$ oxidation in rice fields determined by stable carbon isotopes and specific inhibitors. Global Change Biology 8: 265-280.

34. Barker JF, Fritz $\mathrm{P}$ (1981) Carbon isotope fractionation during microbial methane oxidation. Nature 293: 289-291.
35. Templeton AS, Chu KH, Alvarez-Cohen L, Conrad ME (2006) Variable carbon isotope fractionation expressed by aerobic $\mathrm{CH}_{4}$-oxidizing bacteria. Geochimica Et Cosmochimica Acta 70: 1739-1752.

36. Zhang XY, Zhang GB, Ji Y, Ma J, Xu H, et al. (2012) Straw application altered $\mathrm{CH}_{4}$ emission, concentration and ${ }^{13} \mathrm{C}$-isotopic signature of dissolved $\mathrm{CH}_{4}$ in a rice field. Pedosphere 22: 13-21.

37. Chanton JP (2005) The effect of gas transport on the isotope signature of methane in wetlands. Organic Geochemistry 36: 753-768.

38. Chanton JP, Whiting GJ, Blair NE, Lindau CW, Bollich PK (1997) Methane emission from rice: Stable isotopes, diurnal variations, and $\mathrm{CO}_{2}$ exchange. Global Biogeochemical Cycles 11: 15-27.

39. Tyler SC, Bilek RS, Sass RL, Fisher FM (1997) Methane oxidation and pathways of production in a Texas paddy field deduced from measurements of flux, $\delta^{13} \mathrm{C}$, and $\delta \mathrm{D}$ of $\mathrm{CH}_{4}$. Global Biogeochemical Cycles 11: 323-348.

40. Watanabe A, Satoh Y, Kimura M (1995) Estimation of the increase in $\mathrm{CH}_{4}$ emission from paddy soils by rice straw application. Plant and Soil 173: 225231.

41. Conrad R, Klose M, Yuan Q, Lu Y, Chidthaisong A (2012) Stable carbon isotope fractionation, carbon flux partitioning and priming effects in anoxic soils during methanogenic degradation of straw and soil organic matter. Soil Biology and Biochemistry 49: 193-199.

42. Penning H, Tyler SC, Conrad R (2006) Determination of isotope fractionation factors and quantification of carbon flow by stable carbon isotope signatures in a methanogenic rice root model system. Geobiology 4: 109-121.

43. Penning H, Conrad R (2006) Carbon isotope effects associated with mixed-acid fermentation of saccharides by Clostridium papyrosolvens. Geochimica Et Cosmochimica Acta 70: 2283-2297.

44. Chin KJ, Lueders T, Friedrich MW, Klose M, Conrad R (2004) Archaeal community structure and pathway of methane formation on rice roots. Microbial Ecology 47: 59-67.

45. Lehmann-Richter S, Grosskopf R, Liesack W, Frenzel P, Conrad R (1999) Methanogenic archaea and $\mathrm{CO}_{2}$-dependent methanogenesis on washed rice roots. Environmental Microbiology 1: 159-166.

46. Deuser WG, Degens ET (1967) Carbon isotope fractionation in the system $\mathrm{CO}_{2}$ (gas)- $\mathrm{CO}_{2}$ (aqueous)- $\mathrm{HCO}_{3}{ }^{-}$(aqueous). Nature 215: 1033-1035. 